\title{
Evaluation of Pneumatization in the Articular Eminence and Roof of the Glenoid Fossa with Cone-Beam Computed Tomography
}

\author{
Mehmet İlgüy, Semanur Dölekoğlu, Erdoğan Fişekçioğlu, Nilüfer Ersan, Dilhan İlgüy
}

Department of Dentomaxillofacial Radiology, Yeditepe University Faculty of Dentistry, İstanbul, Turkey

Background: Detection of air cavities, so called pneumatizations, nearby to the temporomandibular joint (TMJ) area is important, as they represent sites of minimal resistance and facilitate the spread of various pathologies into the joint as inflammation, tumor or fractures and serve as a possible complicating factor in TMJ surgery.

Aims: To determine the prevalence of pneumatization of the articular eminence (PAT) and roof of the glenoid fossa (PRGF) using cone-beam computed tomography (CBCT).

Study Design: Cross-sectional study.

Methods: Acquired images of 111 patients (222 TMJs) were evaluated. The presence of pneumatization was recorded at the articular eminence and roof of the glenoid fossa. Age and gender were recorded for all patients and type (unilocular or multilocular) and laterality were noted for the cases of pneumatization.

Results: The mean age of the study group was $48.86 \pm 18.31$ years. Among all the patients, 73 (65.8\%) had PAT, while $13(11.7 \%)$ had PRGF. Forty-two $(37.8 \%)$ of the patients had PAT bilaterally; whereas 3 of them $(2.7 \%)$ presented PRGF bilaterally. The percentage of PAT was higher for females $(73.6 \%)$ than males $(51.3 \%)(\mathrm{p}<0.05)$.

Conclusion: CBCT images are an accurate and reliable means of detection of the exact size and type of pneumatization and the relationship of pneumatization to the adjacent tissues. This is especially significant before a surgical intervention is planned in this region, in order to make a sound diagnosis.

Keywords: Cone-Beam Computed Tomography, pneumatization, temporomandibular joint
Pneumatizations are air filled cavities that are commonly found in the skull. When they exist within the zygomatic process of the temporal bone, they are known as the pneumatized articular eminence (PAT) and the roof of the glenoid fossa (PRGF) $(1,2)$. There is wide variability in the extent of temporal aeration. In some patients, air cells are limited to the roof of the temporomandibular joint (TMJ) fossa, whereas they extend into the articular eminence in others $(1,3)$. The air cells in the root of the zygomatic arch and in the articular eminence of the temporal bone were defined as PAT by Tyndall and Matteson
(4). Detection of these air cavities close to the TMJ is important as they represent sites of minimal resistance and facilitate the spread of various pathologies into the joint as inflammation, tumor or fractures (1). In previous studies, conventional imaging techniques, which were taken during routine examination, were mostly used to evaluate these defects (5-9). As is already known, these techniques are inadequate for TMJ imaging because of the anatomical complexity of this region. Cone beam computed tomography (CBCT) has recently been developed as an alternative imaging technique to conventional $\mathrm{CT}$ for dental

This study was presented at the $19^{\text {th }}$ Balkan Stomatological Society (BaSS) Congress, 24-27 April 2014, Belgrade, Serbia.

Address for Correspondence: Dr. Dilhan İlgüy, Department of Dentomaxillofacial Radiology, Yeditepe University Faculty of Dentistry, İstanbul, Turkey Phone: +905325626256 e-mail: dilhan.ilguy@yeditepe.edu.tr

Received: 18.03.2014 Accepted: 13.11.2014 • DOI: 10.5152/balkanmedj.2015.15193

Available at www.balkanmedicaljournal.org 

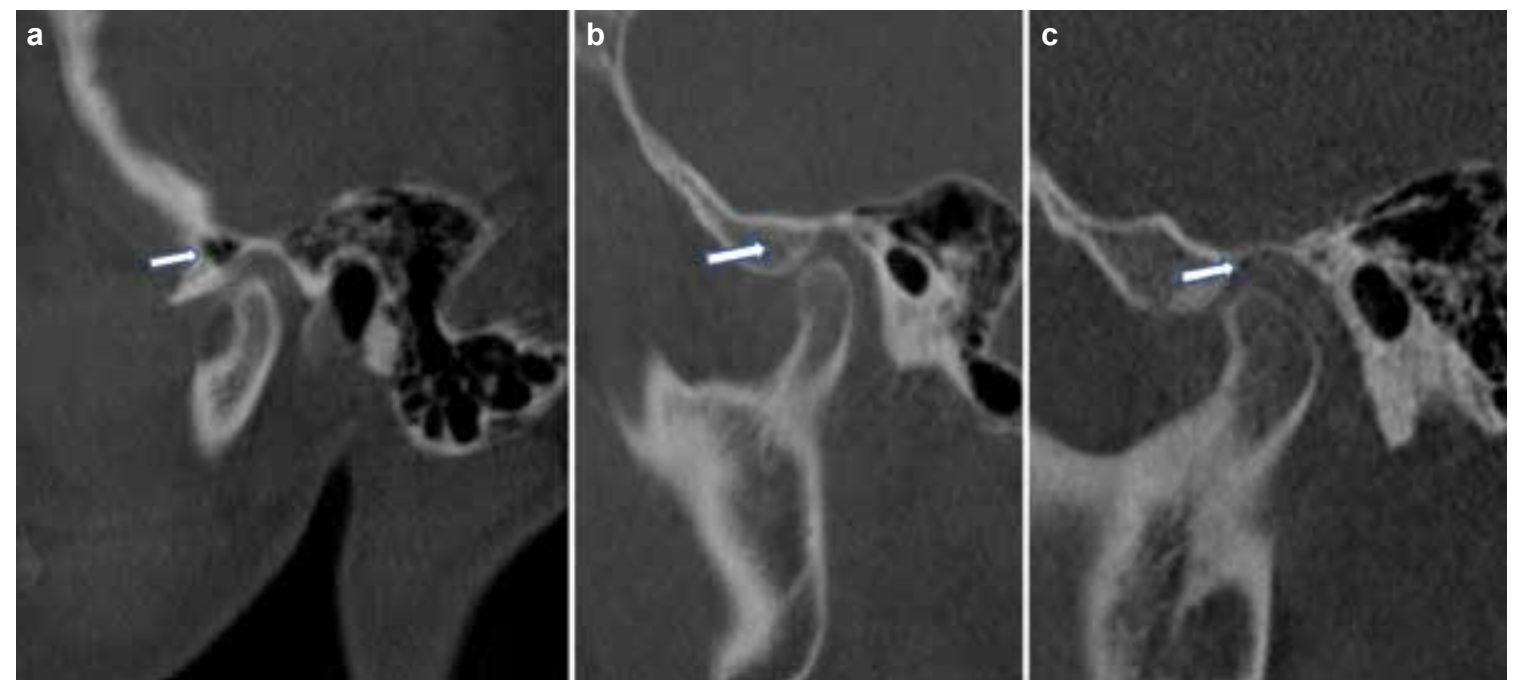

FIG. 1. a-c. Sagittal cone beam computed tomography images of a unilocular pneumatized articular eminence (a), a multilocular pneumatized articular eminence (b), a multilocular pneumatized roof of the glenoid fossa (c)

and maxillofacial diagnostic purposes. It was shown that $\mathrm{CBCT}$ gives superior results for TMJ imaging (10).

A review of the published literature revealed that only one study has been performed on the prevalence of both PAT and PRGF using CBCT (2). The pneumatization of the glenoid fossa has the same clinical significance with PAT in the spread of pathologies into the joint and as a possible complicating factor in TMJ surgery. Thus, further research is necessary to determine the prevalence and clinical relevance of these anatomical structures.

The aim of this study was to define the prevalence of PAT and PRGF using CBCT.

\section{MATERIALS AND METHODS}

The study design received approval from the Ethics Committee in Research. Using power analysis, the sample size was determined as $\mathrm{n}: 51$ where $\Delta: 0.5$, Power: 0.90 and $\alpha$ : 0.05 for the prevalence of PAT according to gender. Overall, 111 patients were selected and the selection of the patients was made among those with existing CBCT scans in the department archive. Thirty-nine of the patients were male, while 72 were female. The age of the patients ranged from 17 to 81 years. Patients with a fracture or pathology in the region of the articular eminence were not included in the study. A CBCT scanner (ILUMA; Imtec Corporation, Oberursel, Germany) with an amorphous silicon flat-panel image detector and a cylindrical volume of reconstruction of up to $19 \times$ $24 \mathrm{~cm}$ was used to take the digital images, at $120 \mathrm{kVp}, 3.8$ $\mathrm{mA}$, and a voxel size of $0.2 \mathrm{~mm}$, with an exposure time of 40 seconds. 3D reconstructions were created by axial CBCT scans, reformatted on a local workstation with ILUMA dental imaging software (ILUMA dental imaging software; Imtec Corporation, Oberursel, Germany) and the images were oriented before measurements. Written informed consent was taken from each patient.

\section{Evaluation of the images}

A specialist in dentomaxillofacial radiology assessed the images in a darkened quiet room with dual monitors (HP LP2475W; Hewlett-Packard Company, California, US, resolution $1920 \times 1200$ ). One viewing session was limited to 30 minutes. The contrast and brightness of the images were adjusted using the image-processing tool in the software to ensure optimal visualization. For the prevention of a possible technical error, the same observer evaluated the measurements for a second time after two weeks.

The presence of pneumatization was recorded at the articular eminence and roof of the glenoid fossa. Identification of PAT on the images was achieved only if the characteristics described by Tyndall and Matteson (4) were found: a radiolucent defect in the zygomatic process of the temporal bone with the appearance similar to mastoid air cells, extending anteriorly to the articular eminence but not beyond the zygomaticotemporal suture, with no enlargement or cortical destruction of the zygoma. If the radiolucent defect was located on the roof of the glenoid fossa above the condyle, it was defined as PRGF. The defects were also classified as unilocular or multilocular. Unilocular pneumatization was a single radiolucent oval defect with well-defined bony borders, whereas multilocular pneumatization described numerous radiolucent small cavities (Figure $1 \mathrm{a}-\mathrm{c}$ ). All data were recorded on both sides. Consequently, 222 sites were analyzed. The frequency of pneuma- 
TABLE 1. Prevalence of pneumatization cases regarding with the localization, laterality and type on $\mathrm{CBCT}$ images

\begin{tabular}{lccc}
\hline & Sample & $\begin{array}{c}\text { PAT-CBCT } \\
\mathrm{n}(\%)\end{array}$ & $\begin{array}{c}\text { PRGF-CBCT } \\
\mathrm{n}(\%)\end{array}$ \\
\hline $\begin{array}{l}\text { Articular eminence and } \\
\text { roof of the glenoid fossa }\end{array}$ & 222 & $115(51.8)$ & $16(72)$ \\
Unilocular & & $16(13.9)$ & $12(75.0)$ \\
Multilocular & & $99(86.1)$ & $4(25.0)$ \\
$\begin{array}{l}\text { Individuals } \\
\quad \text { Unilateral }\end{array}$ & 111 & $73(65.8)$ & $13(11.7)$ \\
\multicolumn{1}{c}{ Bilateral } & & $31(27.9)$ & $10(9.0)$ \\
\hline
\end{tabular}

PAT: pneumatization of the articular eminence

PRGF: pneumatization in roof of glenoid fossa

CBCT: cone-beam computed tomography

n: sample size

tization in accordance with gender, age and remaining teeth was determined.

SPSS 15.0 (Statistical Package for Social Sciences; IBM, New York, USA) for Windows ${ }^{\circledR}$ was used for statistical analysis of the results. The kappa value was used to determine internal consistency. The chi-square test was used compare to the differences between the variables. Significance was accepted at $\mathrm{p}<0.05$.

\section{RESULTS}

The sample included in this study consisted of CBCT images of 111 patients and 222 regions of interest (articular eminence and roof of the glenoid fossa). The mean age of the study group was $48.86 \pm 18.31$ years. Internal consistency of the inter-ratings of the observer for PAT and PRGF were found to be 0.79 and 0.83 on CBCT scans.

Seventy-three $(65.8 \%)$ individuals presented PAT, while $13(11.7 \%)$ had PRGF. Forty-two (37.8\%) of the patients had PAT bilaterally, while $3(2.7 \%)$ of them presented PRGF bilaterally. Table 1 shows the results for prevalence, distribution of laterality and type of both pneumatizations on CBCT scans. The sample was divided into age groups and there was no statistically significant difference between age groups and the presence of PAT and PRGF $(p>0.05)$. The percentage of PAT was higher for females $(73.6 \%)$ than males $(51.3 \%)$ on CBCT scans $(\mathrm{p}<0.05)$. For PRGF, no statistically significant correlation was found with gender. However, no significant correlation was found between the PAT/PRGF and the number of remaining teeth $(\mathrm{p}>0.05)$.

\section{DISCUSSION}

The development of air cells is preceded by the formation of bone cavities, a normal physiological process related to peri- osteal activity. Diagnosis of pneumatization of the articular eminence and TMJ fossa is important because it is a defect that facilitates the spread of various disease processes along the joint, including tumors, inflammation, and fractures due to minimal resistance (11). Also, in cases where it is necessary to surgically manipulate the articular eminence, PAT should be considered a complicating factor $(4,12)$. Determination of these structures prior to surgical intervention may be helpful in the prevention of possible complications.

Radioanatomical knowledge of the structures provides useful information to understand the spreading pattern and differential diagnosis of pathological entities located in this area (13). Laderia et al. (2) specifically drew attention to the necessity of awareness regarding this anatomical aberration which is also likely to occur in the glenoid fossa as well as the articular eminence.

It is known that accessory air cells begin to pneumatize after puberty and achieve their full size after several years, as is the case with proper mastoid air cells. In the present study, the mean age of patients with PAT was 48.86 years, which is similar to that found in the literature ranging between 43.0 and 45.9 years $(2,6,8)$. In the present study, although pediatric patients were not included, the age range was wide $(17-81$ years), in accordance with other studies $(2,5,8,9)$. In the present study in the age group of $17-20$, only 6 patients had PAT and 1 had PRGF.

The incidence of PAT was previously assessed on panoramic radiographs, and the prevalence was reported to be between $1 \%$ and $3.42 \%(4,6,8,9,13,14)$. In the literature, a few studies have assessed the prevalence of PAT on CBCT images (2, 15). The first study performed by Miloglu et al. (13) reported a rate of $8 \%$. The second study by Ladeira et al. (2) also stated a higher rate $(21.3 \%)$. In the present study, the prevalence of PAT on CBCT scans was found to be $51.8 \%$.

Previous studies have shown that the unilateral to bilateral ratio was $2.5: 1$ in cases of PAT. In the present study, bilateral cases $(37.8 \%)$ were higher than unilateral ones $(27.9 \%)$. A predisposing factor for pneumatization could not be found in this study, as in previous ones.

In terms of the type of pneumatization, most researchers found an almost equal distribution of unilocular and multilocular types $(5,8,9,10,14,15)$, except Orhan et al. (15) and Laderia et al. (2), who reported a higher incidence of the multilocular type (75\% and $98.7 \%$, respectively). The present study determined a higher prevalence of the multilocular type for PAT (86.1\%, Table 1). CBCT was used for this study because it shows clear images of air cells in the region of the temporal bone and allows accurate anatomical localization. CBCT has also shown superior results for imaging the TMJ $(2,16,17)$. The use of CBCT, which provides more detail, increases the percentage of PAT. 
In this study, a correlation was found between gender and the percentage of PAT, with females $(73.6 \%)$ being more predisposed than males $(51.3 \%)$ on CBCT scans. On the other hand, no correlation was found for PRGF. These data are not consistent with the results of the previous studies, which found no difference between females and males $(2,18)$.

In terms of PRGF, previous studies performed by Laderia et al. and Groell et al. reported the prevalence to be $38.3 \%$ and $51 \%$, respectively $(1,2)$. These studies differ in sample size and composition of the populations. In the present study, the prevalence was found to be $11.7 \%$. The prevalence reported by Groell et al. was higher compared to our results. This difference might be attributed to the sample source, as Groell et al. studied an Austrian population whereas this study included Turkish Caucasian patients. Although not as high as that reported by Groell et al., Laderia et al. also reported a higher prevalence than the one found in this study. Laderia et al. also studied a Caucasian population; however, their results were higher than ours. It can be speculated that this result might be attributed to the larger sample size of their study.

It is also noteworthy to mention that if a pneumatization is observed located in this area, radiolucent lesions of the bone should also be taken into consideration. Temporal air spaces have been recognized as an important contributor and path in suppuration of various pathological processes. Tumors of the mastoid process and ear may extend into the TMJ whereas otitis media or otomastoiditis may involve the TMJ and can even result in ankylosis (19-23).

In conclusion, CBCT images are accurate and reliable means to detect the exact size and type of pneumatization and their relationship to adjacent tissues. This is especially significant before a surgical intervention is planned in this region, in order to make a sound diagnosis. Further research is warranted in larger populations and specific groups of patients to provide a clearer picture of this clinically relevant issue.

Ethics Committee Approval: Ethics committee approval was received for this study from the ethics committee of the Ethics Committee in Research.

Informed Consent: Written informed consent was taken from the patients.

Peer-review: Externally peer-reviewed.

Author contributions: Concept - M.I., D.I.; Design - M.I., D.I., S.D.; Supervision - M.I., D.I.; Data Collection\&/or Processing - D.I., S.D.; Analysis\&/or Interpretation - E.F.; Literature Search - E.F., N.E.; Writing - D.I., N.E.

Conflict of Interest: No conflict of interest was declared by the authors.
Financial Disclosure: The authors declared that this study has received no financial support.

\section{REFERENCES}

1. Groell R, Fleischmann B. The pneumatic spaces of the temporal bone: relationship to the temporomandibular joint. Dentomaxillofac Radiol 1999;28:69-72. [CrossRef]

2. Ladeira DB, Barbosa GL, Nascimento MC, Cruz AD, Freitas DQ, Almeida SM. Prevalence and characteristics of pneumatization of the temporal bone evaluated by cone beam computed tomography. Int J Oral Maxillofac Surg 2013;42:7715. [CrossRef]

3. Sümbüllü MA, Caglayan F, Akgül HM, Yilmaz AB. Radiological examination of the articular eminence morphology using cone beam CT. Dentomaxillofac Radiol 2012;41:234-40. [CrossRef]

4. Tyndall DA, Matteson SR. Radiographic appearance and population distribution of the pneumatized articular eminence of the temporal bone. J Oral Maxillofac Surg 1985;43:493-7. [CrossRef]

5. Orhan K, Delilbasi C, Cebeci I, Paksoy C. Prevalence and variations of pneumatized articular eminence: a study from Turkey. Oral Surg Oral Med Oral Pathol Oral Radiol Endod 2005;99:349-54. [CrossRef]

6. Kaugars GE, Mercuri LG, Laskin DM. Pneumatization of the articular eminence of the temporal bone: prevalence, development, and surgical treatment. J Am Dent Assoc 1986;113:55-7. [CrossRef]

7. Carter LC, Haller AD, Calamel AD, Pfaffenbach AC. Zygomatic air cell defect (ZACD). Prevalence and characteristics in a dental clinic outpatient population. Dentomaxillofac Radiol 1999;28:116-22. [CrossRef]

8. Hofmann T, Friedrich RE, Wedl JS, Schmelzle R. Pneumatization of the zygomatic arch on pantomography. Mund Kiefer Gesichtschir 2001;5:173-9. [CrossRef]

9. Yavuz MS, Aras MH, Güngör H, Büyükkurt MC. Prevalence of the pneumatized articular eminence in the temporal bone. $J$ Craniomaxillofac Surg 2009;37:137-9. [CrossRef]

10. Barbosa GL, Nascimento MD, Ladeira DB, Bomtorim VV, da Cruz AD, Almeida SM. Accuracy of digital panoramic radiography in the diagnosis of temporal bone pneumatization: A study in vivo using cone-beam-computed tomography. J Craniomaxillofac Surg 2014;42:477-81. [CrossRef]

11. Betz BW, Wiener MD. Air in the temporomandibular joint fossa: CT sign of temporal bone fracture. Radiology 1991;180:463-6. [CrossRef]

12. Kulikowski BM, Schow SR, Kraut RA. Surgical management of a pneumatized articular eminence of the temporal bone. J Oral Maxillofac Surg 1982;40:311-3. [CrossRef]

13. Miloglu O, Yilmaz AB, Yildirim E, Akgul HM. Pneumatization of the articular eminence on cone beam computed tomography: prevalence, characteristics and a review of the literature. Dentomaxillofac Radiol 2011;40:110-4. [CrossRef]

14. Orhan K, Delilbasi C, Orhan AI. Radiographic evaluation of pneumatized articular eminence in a group of Turkish children. Dentomaxillofac Radiol 2006;35:365-70. [CrossRef] 
15. Orhan $\mathrm{K}, \mathrm{Oz} \mathrm{U}$, Orhan AI, Ulker AE, Delilbasi C, Akcam O. Investigation of pneumatized articular eminence in orthodontic malocclusions. Orthod Craniofac Res 2010;13:56-60. [CrossRef]

16. Mischkowski RA, Pulsfort R, Ritter L, Neugebauer J, Brochhagen HG, Keeve E, et al. Geometric accuracy of a newly developed cone-beam device for maxillofacial imaging. Oral Surg Oral Med Oral Pathol Oral Radiol Endod 2007;104:551-9. [CrossRef]

17. Honey OB, Scarfe WC, Hilgers MJ, Klueber K, Silveira AM, Haskell BS, et al. Accuracy of cone-beam computed tomography imaging of the temporomandibular joint: comparisons with panoramic radiology and linear tomography. Am J Orthod Dentofacial Orthop 2007;132:429-38. [CrossRef]

18. White SC, Pharoah MJ. Oral Radiology Principles and Interpretation. $6^{\text {th }}$ ed. Mosby Elsevier; 2009.
19. Thomson HG. Septic arthritis of the temporomandibular joint complicating otitis externa. J Laryngol Otol 1989;103:319-21. [CrossRef]

20. Faerber TH, Ennis RL, Allen GA. Temporomandibular joint ankylosis following mastoiditis: a report of a case. J Oral Maxillofac Surg 1990;48:866-70. [CrossRef]

21. Dingle AF. Fistula between the external auditory canal and the temporomandibular joint: a rare complication of otitis externa. $J$ Laryngology Otol 1992;106:994-5. [CrossRef]

22. Hadlock TA, Ferraro NF, Rahbar R. Acute mastoiditis with temporomandibular joint effusion. Otolaryngol Head Neck Surg 2001;125:111-2. [CrossRef]

23. Orhan K, Nishiyama H, Tadashi S, Shumei M, Furukawa S. MR of 2270 TMJs: prevalence of radiographic presence of otomastoiditis in temporomandibular joint disorders. Eur J Radiol 2005;55:102-7. [CrossRef] 